\title{
A PAISAGEM DA CAATINGA: UM GESTO DE BURLE MARX NA PRAÇA EUCLIDES DA CUNHA
}

\author{
THE LANDSCAPE OF THE CAATINGA: A GESTURE OF BURLE MARX \\ IN THE EUCLIDES DA CUNHA SQUARE
}

\section{Eline Silva de Paula}

Geógrafa e mestranda do Programa de Pós-Graduação em Geografia da UFPE eline.geo@gmail.com

\section{Joelmir Marques da Silva}

Biólogo, mestrando do Programa de Pós-Graduação em Desenvolvimento Urbano (MDU) da UFPE e pesquisador do Laboratório da Paisagem - DAU-UFPE

joelmir_marques@hotmail.com

\section{Patrícia Carneiro de Menezes}

Arquiteta, urbanista e pesquisadora do Laboratório da Paisagem - DAU-UFPE

titacmenezes@gmail.com

\author{
Ana Rita Sá Carneiro \\ Arquiteta e urbanista, PhD, professora da graduação em Arquitetura e Urbanismo e da Pós-Graduação em \\ Desenvolvimento Urbano (MDU) do Departamento de Arquitetura e Urbanismo da UFPE, coordenadora \\ do Laboratório da Paisagem - DAU-UFPE e membro do Conselho Internacional de Jardins Históricos \\ (ICOMOS-IFLA) e do Centro de Estudos Avançados da Conservação Integrada (CECI) \\ anaritacarneiro@hotmail.com
}

\section{Vera Lúcia Mayrinck Oliveira Melo}

Arquiteta e urbanista, doutora e professora da graduação em Arquitetura e Urbanismo e da PósGraduação em Desenvolvimento Urbano (MDU) do Departamento de Arquitetura e Urbanismo da UFPE e coordenadora do Núcleo Paisagem e Cultura

veramelo@hotlink.com.br

\section{RESUMO}

Ao projetar a praça Euclides da Cunha em 1935, o paisagista Roberto Burle Marx teve a intenção de criar um jardim temático de plantas do sertão em uma área litorânea. Introduzindo plantas da paisagem da caatinga, Burle Marx não apenas valorizou a vegetação nativa, como trouxe ao habitante da cidade o conhecimento de nossas riquezas naturais, chamando a atenção para o fato de a parcela de nossa flora estar sendo dizimada. Nesse contexto, o presente artigo pretende identificar, na paisagem da praça Euclides da Cunha, uma representação da caatinga, e, assim, garantir medidas de conservação que preservem sua conotação de ecossistema e de monumento. A praça Euclides da Cunha foi restaurada em 2004 pela prefeitura da cidade do Recife em parceria com o Laboratório da Paisagem da Universidade Federal de Pernambuco, fundamentada na Carta de Florença (1981), bem como em estudos detalhados da historiografia da praça e da vegetação da caatinga. Ressalta-se, ainda, que a praça Euclides da Cunha está em processo de tombamento no Instituto do Patrimônio Histórico e Artístico Nacional (Iphan) na categoria de jardim histórico.

Palavras-chave: Roberto Burle Marx, praça Euclides da Cunha, paisagem, caatinga. 


\begin{abstract}
In 1935, the landscape designer Roberto Burle Marx created the Euclides da Cunha Square as a thematic garden of "caatinga" vegetation in Recife, a coast Brazilian city. With this proposal, Burle Marx not only gave artistic and ecological value to the native vegetation, but also had the intention to protect at least part of Brazilian decimated vegetation, and bring to the city dwellers the knowledge of natural resources. In this context, this article attempts to identify the symbolism of the "caatinga" vegetation in the Euclides da Cunha Square landscape to ensure conservation practices that can preserve its ecosystem and monumental significance. The Euclides da Cunha Square was restored in 2004 by Recife's City Council in partnership with the Landscape Laboratory of the Federal University of Pernambuco, based on the Florence Charter (1981) and on detailed studies about square's historiography and "caatinga" ecosystem. It is noteworthy also that Euclides da Cunha Square is being analyzing by the National Institute of Historical and Artistic Heritage to be preserved as historical garden.
\end{abstract}

Keywords: Roberto Burle Marx, Euclides da Cunha square, landscape, caatinga.

\title{
INTRODUÇÃO
}

Jardim é um termo universal conceituado ao longo do tempo e dentro de diversas culturas como parte do conjunto de espaços de lazer que inclui espaços públicos e privados (SÁ CARNEIRO; SILVA; GIRÃO, 2007). Conforme Dourado (1991), a essência do jardim expressa um gesto na paisagem como algo inerente ao convívio do homem com a sociedade, estando inseridos na paisagem das cidades.

No Recife, os jardins constituem uma parte integrante da história da paisagem da cidade que teve início com o parque de Friburgo planejado pelo conde Maurício de Nassau no século 17, e, a partir do século 19, as influências das culturas inglesa e francesa estavam presentes na arte de projetar jardim. Em 1935, com a chegada do paisagista Roberto Burle Marx, uma nova concepção de jardins surgiu no Recife e teve por base o movimento moderno. Ao projetar os jardins, Burle Marx expressa seu respeito pelas características da paisagem local, por meio da utilização da flora autóctone, passando a utilizar a água como um elemento importante no projeto paisagístico. É um jardim que legitima a paisagem regional, que procura se desvincular das influências europeias, firmado em razões culturais de mudança e de identidade nacional para "semear" a alma brasileira.

Com Burle Marx, nasce, no Recife, o jardim moderno, que para ele estava sustentado em três aspectos: a) higiene (representando um pulmão coletivo nas cidades); b) educação (propiciar meios para que os habitantes pudessem distinguir sua própria flora da exótica e, dessa forma, incentivar o amor pela natureza); e c) arte (fornecer ideia básica, com perspectiva lógica e subordinado a uma determinada forma de conjunto). A sua concepção de moderno, conforme Sá Carneiro et al (2007), não se limitava a um espaço fechado, enquadrado por muros e paredes, mas conduzido por um pensamento de organização da natureza, ou seja, voltado para os espaços abertos. São produtos de sua formação artística, que inclui conhecimentos sobre história, botânica, pintura, escultura, música e arquitetura e de suas impressões sobre a paisagem urbana.

Foi no Recife que Burle Marx concebeu os primeiros jardins públicos de sua carreira. Um deles é o jardim das cactáceas, projetado em 1935, e denominado, posteriormente, pelo paisagista de praça Euclides da Cunha, uma homenagem ao jornalista e escritor 
Euclides da Cunha. Nesse jardim privilegiou a vegetação da caatinga, tornando-o o primeiro jardim público essencialmente brasileiro, com a evidente intenção de representar um dos domínios mais singulares de nossa flora em resposta ao que o movimento moderno almejava.

No entanto, com o passar do tempo, o jardim da praça Euclides da Cunha foi se descaracterizando devido à falta de conservação. Em 2003, uma ação conjunta da prefeitura da cidade do Recife com o Laboratório da Paisagem da Universidade Federal de Pernambuco iniciou-se às ações de restauração que terminaram em 2004. A restauração teve como orientação a Carta de Florença (1981), elaborada pelo Conselho Internacional de Monumentos e Sítios (ICOMOS) e pelo Conselho Internacional de Jardins Históricos (ICOMOS/IFLA), pesquisas detalhadas da historiografia da praça, bem como o estudo da vegetação da caatinga para conhecer sua diversidade florística.

No ano de 2009, o Laboratório da Paisagem da UFPE solicitou, ao Instituto do Patrimônio Histórico e Artístico Nacional (Iphan), o tombamento da praça Euclides da Cunha, com as praças de Casa Forte, do Derby, da República, Jardim do Campo das Princesas, praças Faria Neves e Ministro Salgado Filho na categoria de jardim histórico.

Assim, objetivou-se, com o artigo, identificar, na paisagem da praça Euclides da Cunha, uma representação da vegetação da caatinga, e, assim, garantir medidas de conservação que preservem sua conotação de ecossistema e de monumento.

\section{PAISAGEM E ECOLOGIA DA PAISAGEM}

A paisagem ganha sentido ou utilidade pelo olhar do observador, dependendo de sua formação científica e/ou cultural. Diante da diversidade de conceitos para definir "o que é paisagem", a inter-relação do homem com seu ambiente está presente na maior parte deles.

A paisagem sempre é especificada pela subjetividade do observador; subjetividade que é mais do que um simples ponto de vista ótico. Ela é um processo interativo entre o homem e o meio ambiente, no qual atuam todos os sentidos, não só o da visão (BERQUE, 1994; SÁ CARNEIRO, 2002).

Por só existir mediante um observador, a paisagem exerce influência no modo de vida das pessoas, uma vez que atua nas sensações do dia a dia, seja do clima, seja do congestionamento no trânsito, da densidade construtiva, da abertura dos espaços livres, da visibilidade da superfície celeste. Apesar de sua relevância como entidade relacional entre a natureza e a cidade, nem sempre a paisagem é contemplada em projetos e planos urbanísticos e, consequentemente, na legislação urbana das cidades como um item a ser observado e controlado (SÁ CARNEIRO; SILVA; MENEZES, 2010).

As noções globais, espaciais e visuais, consideradas por quem estuda a paisagem, estão também imbuídas nas abordagens atuais de uma nova área do conhecimento, dentro da ecologia, denominada de "ecologia de paisagens".

Conforme Metzger (2001), a ecologia de paisagens refere-se à observação das inter-relações da biota, incluindo o homem, com seu ambiente, formando um todo, e 
caracteriza-se por duas visões distintas de paisagem - uma geográfica e outra ecológica. A visão geográfica foi impulsionada pelo biogeógrafo alemão Carl Troll em 1939 e por pesquisadores essencialmente geógrafos, da Europa Oriental e da Alemanha e teve influência da geografia humana, da fitossociologia e da biogeografia, e de disciplinas da geografia ou da arquitetura relacionadas com o planejamento regional. Já a visão ecológica, mais recente, da década de 1980, foi influenciada pelos biogeógrafos e ecólogos americanos diante das teorias da ecologia de ecossistemas, modelagem e análise espacial.

Considerando os conceitos ora dispostos acima, um exemplo de paisagem construída embasada tanto na teoria da paisagem como na ecologia de paisagens são os jardins projetados por Roberto Burle Marx.

No caso da praça Euclides da Cunha, Burle Marx teve a intenção de criar uma paisagem configurada nos aspectos bióticos e abióticos da caatinga em uma região de domínio atlântico, e isso só foi possível mediante uma investigação e interpretação da paisagem dessa região. Ao projetar o jardim, o paisagista adequou as particularidades climáticas e botânicas daquele ecossistema, preocupando-se com as relações fisionômicas, estruturais e ecológicas.

O uso das espécies nativas seria, além da questão simbólica, mais econômica e ecologicamente correta, e aparece como temática da obra de Burle Marx (OLIVEIRA, 2009). Nas palavras do paisagista, sua obra pretendia:

"formar um vocabulário partindo da riquíssima flora brasileira, de sua infinita variedade, introduzindo no jardim espécies nativas, estudando, apaixonada e constantemente, as associações ecológicas, observando a paisagem natural e lutando pela preservação dessa herança." (MARX, 1987, p. 33).

Assim, o que seria o bioma da caatinga que o paisagista Roberto Burle Marx quis reproduzir em uma área litorânea como a cidade do Recife?

\section{O DOMÍNIO DA CAATINGA}

Sempre é um desafio falar da caatinga, uma vez que se faz necessário, antes de tudo, despir-se de todo e qualquer preconceito criado com relação à diversidade florística, faunística e os aspectos paisagísticos, desprezados por aqueles que desconhecem suas riquezas. Como encontrar beleza em uma vegetação que não apresenta o verde das florestas tropicais úmidas? $\mathrm{O}$ aspecto seco e espinhoso dos cactos e dos arbustos sugere pouca diversidade das espécies e é um lugar inóspito a qualquer forma de vida animal. No entanto, observando a caatinga, é possível enxergar uma diversidade biológica e a peculiar beleza de suas paisagens.

Caatinga, do tupi guarani, "mata branca", caracteriza bem o aspecto da vegetação na estação seca, quando as folhas caem e apenas os troncos brancos e brilhosos das árvores e arbustos permanecem na paisagem (ALBUQUERQUE; BANDEIRA, 1995 apud LEAL; TABARELLI; SILVA, 2008). É o único bioma restrito ao território 
brasileiro, ocupando basicamente a região Nordeste e algumas áreas do estado de Minas Gerais.

O domínio' das caatingas brasileiras é um dos três espaços semiáridos da América do Sul. Fato que o caracteriza como um dos domínios de natureza de excepcionalidade marcante no contexto climático e hidrológico de um continente dotado de grandes e contínuas extensões de terras úmidas (AB'SÁBER, 2003). No Brasil esse domínio é visto como um mosaico de arbustos espinhosos e florestas sazonalmente secas que ocupam cerca de $735.000 \mathrm{~km}^{2}$ do Nordeste. A precipitação média anual varia entre 240 e $1.500 \mathrm{~mm}$, mas $50 \%$ da região recebe menos de $750 \mathrm{~mm}$ e algumas áreas centrais menos de $500 \mathrm{~mm}$ (PRADO, 2003 apud LEAL; TABARELLI; SILVA, 2008). As chuvas irregulares resultam em secas severas, o que torna a vida na caatinga difícil e determinam mudanças adaptativas na biota da região.

Em contraste a esse cenário fisicamente impróprio à aglomeração, a caatinga é um dos biomas mais ameaçados do Brasil. Conforme Leal, Tabarelli e Silva (2008), grande parte da superfície da caatinga já foi modificada e, infelizmente, dentre os espaços limitados por vegetação, é o que dispõe de menor número de unidades de conservação e a menor cobertura vegetal protegida dentre todos os ecossistemas brasileiros, ficando à mercê dos que a denigrem.

Conforme os autores supracitados, existem quatro aspectos pelos quais a caatinga deve ser estudada: a) é a única grande região natural brasileira cujos limites são inteiramente restritos ao território nacional; b) é proporcionalmente a menos estudada entre as regiões naturais brasileiras, com grande esforço científico, estando concentrada em alguns poucos pontos em torno das principais cidades da região; c) é a região natural brasileira menos protegida, pois as unidades de conservação cobrem menos de $2 \%$ de seu território; e d) continua passando por um extenso processo de alteração e deterioração ambiental provocado pelo uso insustentável de seus recursos naturais.

Ao estudar a distribuição da flora pernambucana, Vasconcelos Sobrinho a dividiu em zonas, subzonas e microclimas. Nessa divisão considerou o agreste como uma subzona da caatinga, subdividindo-a em agreste e sertão (EGLER, 1951). Por outro lado, exite a divisão que se refere à caatinga como hipoxerófila e hiperxerófila, feita pelo Ministério da Agricultura, que resume as características das áreas descritas por Vasconcelos Sobrinho.

O agreste se estende entre os limites da serra do Mar a leste, onde as florestas são abundantes, e os interiores mais secos a oeste. Pode ser encontrado do Rio Grande do Norte à Bahia central, onde é substituído, nessa região de transição, pela assim denominada "mata de cipó". Apresenta um regime de chuvas mais abundante, acima de $1.000 \mathrm{~mm} / a n o$, e é menos sujeito às secas catastróficas, uma vez que se beneficia da umidade residual dos ventos de sudeste (PRADO, 2003 apud LEAL; TABARELLI; SILVA, 2008). Já o sertão, termo usado para designar a parte mais seca e mais inóspita da caatinga, rica em espécies xeromórficas, reflete condições mais drásticas no ambiente ${ }^{2}$. Conforme Luetzelburg 3 (1923) apud Egler (1951, p. 84): 
"Nesta determinação o sertanejo não obedece à classificação botânica, atende apenas o aproveitamento útil do terreno para fins agrícolas ou pecuários. Em vista disso determina a parte mais seca e inútil da caatinga de 'sertão', dando ao restante o nome geral de 'caatinga'. [...] Os habitantes da região classificam de 'caatinga legítima' a região onde vegeta o mandacaru (Cereus jamacaru), que é aproveitável para pastagem; enquanto o 'sertão', representado pelo facheiro (Pilosocereus piauhyensis) que não tem utilidade alguma: é região deserta, de difícil trânsito e subsistência."

Observando o trecho descrito acima, vê-se que a importância da vegetação da caatinga é medida por sua utilidade, desprezando sua beleza e fragilidade, julgamento esse que é feito até hoje.

Para elucidar qualquer dúvida quanto à variação fisionômica dessa vegetação, far-se-á necessário buscar a divisão feita pelo Levantamento Exploratório de Solos de Pernambuco de 1951, que divide a caatinga em dois grandes grupos: a caatinga hipoxerófila e a caatinga hiperxerófila (Quadro 1).

Quadro 1: Diferenciação entre as caatingas Hipoxerófila e Hiperxerófila

\begin{tabular}{|c|c|}
\hline Caatinga Hipoxerófila & Caatinga Hiperxerófila \\
\hline $\begin{array}{l}\text { Predomina na região do agreste e nos refúgios } \\
\text { expostos úmidos do sertão }\end{array}$ & $\begin{array}{l}\text { Caracteriza fisiograficamente o sertão } \\
\text { pelas condições áridas }\end{array}$ \\
\hline $\begin{array}{l}\text { Vegetação densa de porte predominante } \\
\text { arbóreo-arbustivo. O estrato arbóreo } \\
\text { compreende espécies de até } 15 \text { metros } \\
\text { representadas pelas famílias Anacardiaceae, } \\
\text { Leguminosae e Cactaceae e o estrato } \\
\text { arbustivo é representado por vegetais de, } \\
\text { aproximadamente, dois metros de altura, } \\
\text { representantes, das famílias Leguminosae, } \\
\text { Euphorbiaceae e Rubiaceae }\end{array}$ & $\begin{array}{l}\text { Vegetação bastante esparsa, formando } \\
\text { moitas. Algumas exceções mostram } \\
\text { relativa densidade com espécies } \\
\text { arbustivas e arbóreas. Predomínio da } \\
\text { vegetação mais baixa, representada } \\
\text { pelas famílias Leguminosae, } \\
\text { Solanaceae, Bignoniaceae, Cactaceae e } \\
\text { Euphorbiaceae }\end{array}$ \\
\hline $\begin{array}{l}\text { Totais pluviométricos mais elevados e chuvas } \\
\text { melhor distribuídas }\end{array}$ & $\begin{array}{l}\text { Totais pluviométricos com distribuição } \\
\text { anual muito dispersa }\end{array}$ \\
\hline $\begin{array}{l}\text { Exemplos de unidades florísticas: catingueira } \\
\text { (Caesalpinia pyramidalis), angico } \\
\text { (Anadenanthera colubrina), braúna (Schinopsis } \\
\text { brasiliensis), juazeiro (Zizyphus joazeiro), } \\
\text { marmeleiro (Croton sonderianus), xique-xique* } \\
\text { (Pilosocereus gounellei) mandacaru (Cereus } \\
\text { jamacaru), ipês (Tabebuia sp.) e aroeira } \\
\text { (Myracrodruon urundeuva) }\end{array}$ & $\begin{array}{l}\text { Exemplos de unidades florísticas: } \\
\text { jurema-preta (Piptadenia moniliformis), } \\
\text { mufumbo (Combretum leprosum), } \\
\text { faveleiro (Cnidoscolus phyllacanthus), } \\
\text { marmeleiro (Croton sonderianus), } \\
\text { coroa-de-frade (Melocactus bahiensis), } \\
\text { palma (Opuntia palmadora), xique- } \\
\text { xique* (Pilosocereus gounellei) e facheiro } \\
\text { (Pilosocereus piauhyensis) }\end{array}$ \\
\hline
\end{tabular}

Fonte: Adaptado de Castro, 2010. * O marmeleiro e o xique-xique são típicos de área de transição (Mata úmida $\rightarrow$ Mata Seca) 
Partindo do litoral pernambucano com destino ao sertão, na seguinte ordem das regiões geográficas: litoral, mata, agreste e sertão, percebe-se claramente a mudança de paisagens. Essas regiões correspondem às respectivas vegetações naturais: vegetação de litoral (alto teor de umidade); mata (arbórea densa); agreste (pouco úmida a seca) e caatinga (seca e bastante árida). Tal configuração pode ser observada na praça Euclides da Cunha. Ao criar um jardim temático em pleno litoral, Burle Marx desafiou as condições fisiográficas para mostrar que o jardim é, sobretudo, uma expressão ecológica. Nessa representação, pôde-se perceber a preocupação do paisagista em adaptar a vegetação não endêmica da área às condições edafo-climáticas e vegetacionais tão distintas.

\section{PRAÇA EUCLIDES DA CUNHA: UMA REPRESENTAÇÃO DA CAATINGA}

Ao projetar várias praças no período em que permaneceu no Recife (1935-1937), Burle Marx criou, seja por meio de pequenas intervenções, seja por projetos completos, um Plano de Aformoseamento que abrangeu 17 jardins (15 deles projetados no período de 1935 a 1937 e dois entre 1957 a 1958). Portanto, foi em Pernambuco que o paisagista desenvolveu uma intensa pesquisa botânica em torno da flora autóctone, constituindo o fundamento do jardim tropical.

Dentre os jardins projetados pelo paisagista, chama-nos a atenção a praça Euclides da Cunha, projetada em 1935, pelo uso da vegetação da caatinga em um projeto paisagístico e por ter sido, conforme Siqueira (2004), o mais polêmico que ele projetou, uma vez que muitos recifenses liderados por Mario Melo, do Instituto Arqueológico do Recife, reagiram ao entender que um jardim com aquelas características seria uma tentativa de devolver a cidade para a selva. A praça Euclides da Cunha está entre os seis jardins para os quais foi solicitado o tombamento ao Instituto do Patrimônio Histórico e Artístico Nacional (Iphan) na categoria de jardim histórico em 2009.

Burle Marx, ao projetar a praça Euclides da Cunha (Figura 1), colocou em relevo uma particularidade climática e botânica até então totalmente ignorada pela sociedade, salvo pelo jornalista e escritor Euclides da Cunha, que, com sua obra literária Os sertões, marco do movimento moderno, expôs suas observações botânicas que contribuiram para o paisagista enriquecer o vocabulário botânico, além da grande experiência vivida nas estufas do Jardim Botânico de Dahlem, conferindo, assim, uma função educativa, ecológica e, ao mesmo tempo, artística ao jardim (LEENHARDT, 2008; SÁ CARNEIRO, 2009).

Conforme relatado por Burle Marx no Jornal Diário da Tarde, de 14 de março de 1935, o jardim seria composto por duas alamedas de árvores autóctones do sertão, que envolveriam a praça pela parte mais externa, encontrando-se em uma das extremidades onde fariam um pequeno bosque. No cactário, localizado na parte central, reuniria o maior número possível de gêneros brasileiros da família Cactaceae, Bromeliaceae e Euphorbiaceae, bem como blocos de pedras completando o ambiente nordestino. 
Dessa forma, utilizou várias espécies e entre elas destacam-se o umbuzeiro (Spondias tuberosa), juazeiro (Zizyphus joazeiro), ipês (Tabebuia sp.), mandacaru (Cereus jamacaru), coroa-de-frade (Melocactus bahiensis), palma (Opuntia palmadora), xique-xique (Pilosocereus gounellei) e facheiro (Pilosocereus piauhyensis).
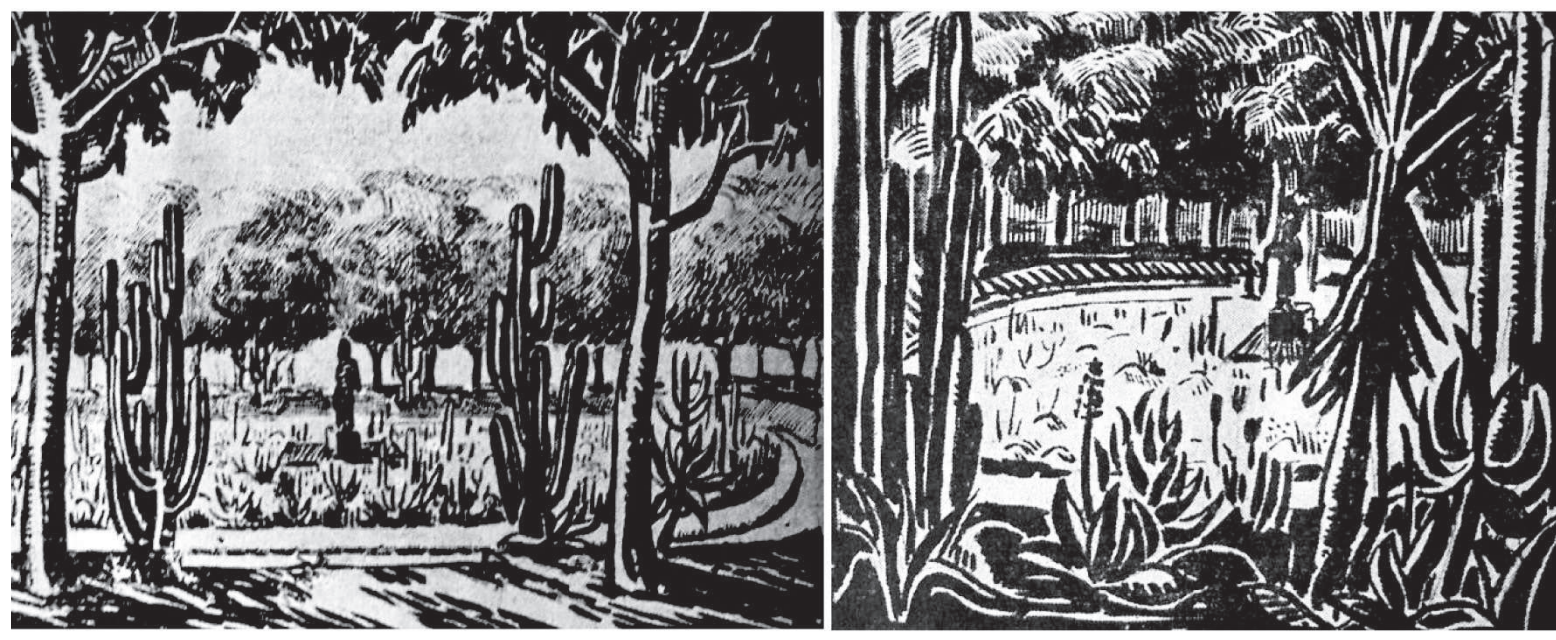

Figura 1: Desenhos de Burle Marx da praça Euclides da Cunha, 1935

Fonte: Diário da Tarde, de 14 março de 1935

Assim, e tomando como base a descrição no item 2 referente à caatinga, é perceptível, na praça Euclides da Cunha, elementos inerentes a essa paisagem. Burle Marx dispõe a vegetação arbórea com a função de proteger o canteiro central, representado, em sua maioria, por cactáceas, dos ventos advindos do litoral, visto que tal vegetação não suporta alta umidade.

No sentido borda-centro do jardim, foram dispostas espécies arbóreas no primeiro anel caracterizadas por espécies hipoxerófilas adaptadas à umidade; logo depois, outro anel composto por espécies arbóreas e arbustivas, vegetação de transição, com a função de absorver a umidade que conseguiu ultrapassar a vegetação do primeiro anel, assim permitindo que a vegetação do cactário esteja livre da umidade, além de receber incidência solar direta (Figura 2). E, nas palavras de Burle Marx, "as alamedas serviram ainda como efeito de perspectiva para acentuar a luminosidade do cactário" (MARX, 1935).

No entanto, Burle Marx, além de introduzir a vegetação da caatinga, consegue também estabelecer uma relação ecofisiológica, e dessa forma, propiciam ao vegetal condições para que viva em ressonância com o meio. Isso se deve à sua capacidade de observação aos pontos fundamentais como conhecer a planta em seu hábitat, considerá-la como elemento de uma paisagem, compreender suas associações, sua importância fitossociológica, enfim, como ela está inserida no meio físico natural (condições edafo-climáticas), que, para o jardim, é de extrema importância, uma vez que, para Burle Marx, fazer jardim era também criar microclimas.

A defesa que Burle Marx fez da utilização da vegetação da caatinga no Recife não se baseava apenas em suas qualidades paisagísticas intrínsecas, mas, sobretudo, por ser nativa da região. Conforme Leenhardt (2008), tais espécies jamais tiveram direito 
de cidadania na prática paisagística da época. A maneira de apresentá-las é decisiva para a significação que elas terão no jardim. Então, Burle Marx afirma: "Pernambuco possuirá no que se refere a jardim, algo sólido e de definitivo com que se apresentar a posteridade, dentro de uma expressão de arte, cultura e bom senso." (MARX, 1935, p. 1)

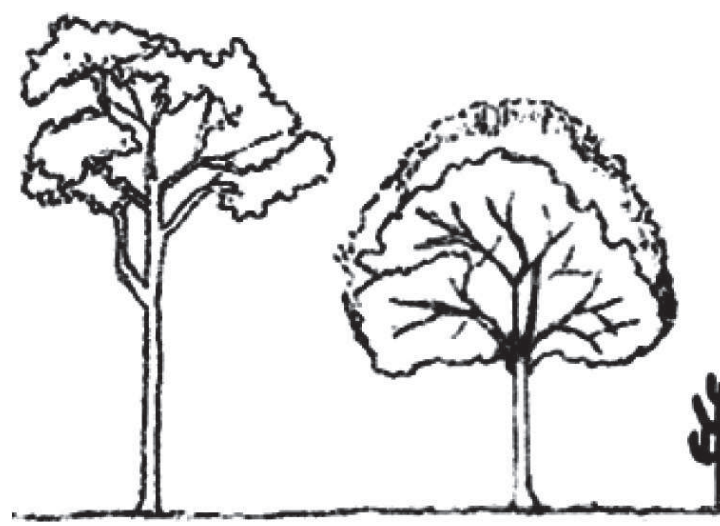

Primeiro anel
Segundo anel

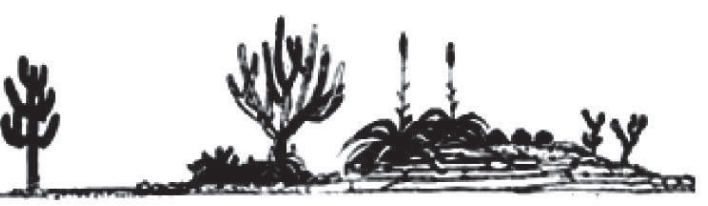

Cactário

Borda

\section{Centro}

Figura 2: Perfil da vegetação da praça Euclides da Cunha, segundo disposição da vegetação nos anéis, adaptado dos desenhos da arquiteta Liana Mesquita para estudo da vegetação da caatinga

Fonte: Laboratório da Paisagem - UFPE

A paisagem é tida por Burle Marx como todo e qualquer ambiente de nosso território e também tudo o que está em nosso domínio visual. Ele sempre estava à procura de uma ordem, um ritmo, uma associação de volumes ou texturas, na qual a intenção humana em reorganizar elementos da natureza cria uma paisagem construída como obra de arte (COSTA, 1999). Segundo Burle Marx (1987), para fazer um jardim é preciso entender o ambiente, o meio ambiente. E temos de compreender a importância da utilização das plantas da natureza e, a partir delas, construir jardins pelo e para o homem (grifo nosso).

Dessa forma, o projeto paisagístico, no entanto, busca a criação de um mundo, de uma nova realidade. Muitas vezes pode haver um grande prejuízo quando o autor do jardim não consegue compreender a realidade natural do local, aquilo que não foi elaborado pelo homem, o que o impossibilitará de criar algo devidamente relacionado com o preexistente (COSTA, 1999; GUERRA, 2002).

Com o passar do tempo, e aliado à falta de conservação, a praça Euclides da Cunha entrou em processo de descaracterização. Vegetação arbórea que não fazia parte do projeto original foi propagada por mendigos que usavam o local como abrigo e estabilizaram-se no canteiro central, ocasionando sombreamento permanente sob as cactáceas que resistiram até a década de 1980.

Diante do processo de descaracterização, uma parte da memória paisagística do Recife estava se perdendo. Em vista disso, a prefeitura do Recife, junto do Laboratório da Paisagem da Universidade Federal de Pernambuco, iniciaram, em 2001, as discussões 
sobre o processo de restauração do jardim o qual se fundamentou na Carta de Florença, de 1981, bem como em estudos detalhados da historiografia da praça. Além disso, foram realizados estudos detalhados da vegetação da caatinga para demonstrar sua diversidade e, dessa forma, convencer a equipe da prefeitura da cidade do Recife, que seria responsável por uma experiência pioneira de restauração de um jardim histórico de Burle Marx (SÁ CARNEIRO; SILVA; MENEZES, 2010).

Em 2003, deu-se início à restauração que foi concluída em maio de 2004 (Figura 3). $O$ manejo de 25 árvores invasoras, em sua maioria espécies frutíferas com problemas fitossanitários, configurou o primeiro momento. Em seguida, por problemas de drenagem, houve a elevação do terreno do canteiro central visando à fixação da vegetação. As espécies utilizadas no restauro foram trazidas da sementeira da Companhia Hidrelétrica do São Francisco (CHESF), instalada no sertão do estado de Alagoas. No que se refere às espécies arbóreas, 48 indivíduos foram plantados os quais, somados aos existentes, totalizaram 84 indivíduos (SÁ CARNEIRO, 2009).
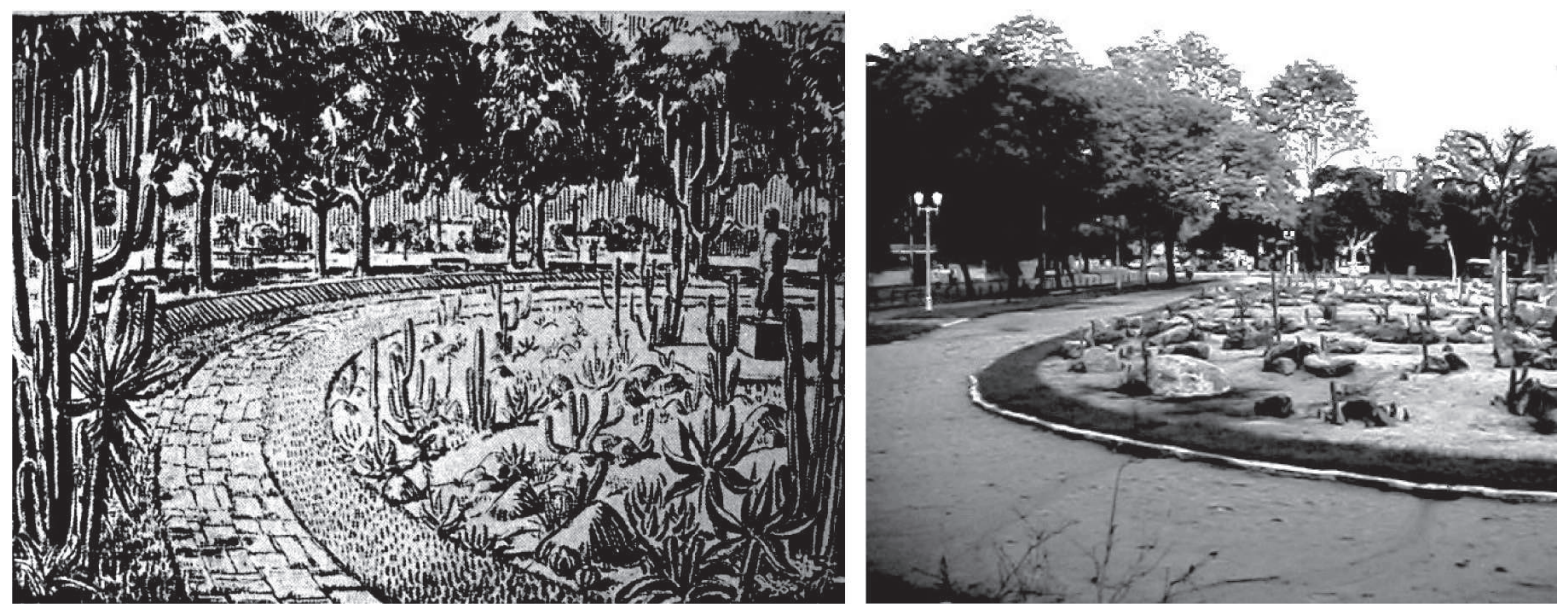

Figura 3: Desenho de Burle Marx da praça Euclides da Cunha, 1935 (à esquerda)

Fonte: Diário da Tarde, 14 março de 1935; e vista parcial da praça Euclides da Cunha restaurada, 2004 (à direita) - Acervo do Laboratório da Paisagem-UFPE

Após o restauro, e aí já se vão sete anos, a praça Euclides da Cunha vem passando por constante manutenção, principalmente no cactário, garantindo, dessa forma, a proteção contínua e sua subsistência.

\section{PROTEÇÃO DE JARDINS HISTÓRICOS}

Ao projetar com vegetação, ou seja, com seres vivos que possuem um ciclo de vida, os espaços projetados sofrem constantes transformações ao longo do tempo. De acordo com Leenhardt (2008), o passar do tempo não é, para o jardim, uma degradação, mas um processo normal, e sua ocorrência se revela na dinâmica própria de sua evolução.

A planta, por sua vez, goza no mais alto grau da propriedade de ser instável, sofre uma mutação constante, um desequilíbrio permanente, cuja finalidade é a própria 
busca de equilíbrio. A planta vive em ressonância com o meio e há uma correspondência entre as condições do nicho que ela ocupa e de suas exigências para nascer, crescer e reproduzir. A vida de um vegetal é uma atividade cíclica, cujas pausas são marcadas pela morte e pela germinação (MARX, 1987).

Mesmo sendo considerados ecossistemas, desempenhando funções de atrair e alimentar a fauna, melhorar o microclima local, atuar como filtros que atenuam os níveis de polvição, os jardins históricos também são monumentos e, como tal, devem apresentar o testemunho de uma época e de um fazer, ou seja, sua autenticidade e integridade, e, dessa forma, a intervenção do homem sobre o jardim se faz necessária (DELPHIM, 2005). Logo, medidas de proteção que garantam sua conotação, tanto de ecossistema como de monumento devem ser aplicadas.

A autenticidade e integridade são premissas que devem ser atendidas para que um jardim possa ser configurado como histórico (DE ANGELIS; DE ANGELIS NETO, 2004) e a esse respeito, afirma o arquiteto Carlos Fernando de Moura Delphim, membro do Iphan, em entrevista concedida à engenheira florestal e estudiosa dos jardins de Burle Marx, Ana Rosa de Oliveira, em 2003:

"[...] Diz-se que um bem é integro se há uma relação equilibrada e harmônica entre os diferentes elementos de um sistema. Quanto à autenticidade, tem a ver com o grau de originalidade dos elementos. Sobretudo em um jardim, em que sucessivas alterações vão se processando ao longo de sua história, é necessário, primeiro verificar quão integro ele se encontra e, em seguida, quão autentico" Estas condições são importantes para justificar medidas para preservação de todo bem cultural, inclusive os jardins históricos, e constituem a premissa de qualquer trabalho, inclusive de tombamento (grifo nosso)."

A preocupação com a vegetação do jardim surge de forma oficial a partir da Carta de Atenas (1931), associada à valorização dos monumentos. Na referida carta é especificado: "deve-se também estudar as plantações e ornamentações vegetais convenientes a determinados conjuntos de monumentos para lhes conservar o caráter antigo."

Dessa maneira, com o objetivo de preservar os jardins e sítios históricos abordados na então Carta de Veneza (1934), o comitê de jardins históricos reunidos em Florença (Itália), em 1981, elabora a Carta de Florença destinada à proteção dos jardins históricos, considerando-os como monumentos vivos.

Para a proteção do jardim, exige-se que o mesmo seja identificado e inventariado. Conforme o artigo 9 da Carta de Florença, no jardim deve haver intervenções diferenciadas de manutenção, conservação e restauração. E em determinados casos recomenda-se a recuperação. Contudo, de acordo com Delphim (2005), preservar os jardins históricos é um ato de respeito à vida, ao equilíbrio ambiental, à obra e ao legado humano. Defendê-los é introduzir gerações contemporâneas e futuras a atitudes de maior zelo por esse patrimônio. Os jardins históricos são o mais rico exemplo de testemunho da relação entre a cultura e a natureza, testemunho que se 
preserva no caráter das intervenções realizadas no local e no estado de espírito dos que os usufruem.

Para o caso dos jardins de Burle Marx no Recife, deve-se ressaltar, como ação de conservação, a elaboração do Inventário dos Jardins de Burle Marx no Recife, elaborado pelo Laboratório da Paisagem da Universidade Federal de Pernambuco. O inventário gerou a cartilha Os jardins de Burle Marx no Recife, produzida em 2009 pelo Laboratório da Paisagem da UFPE e editada pela prefeitura da cidade do Recife, um instrumento de educação patrimonial. A partir do inventário, indicadores para a conservação de tais jardins, que inclui a praça Euclides da Cunha, estão sendo elaborados, dando ênfase aos aspectos históricos, ecológicos, botânicos, artísticos, sociais, arquitetônicos e espirituais.

Vale ressaltar ainda que outros instrumentos têm sido produzidos mundialmente como a Lei e Regulamento de Proteção, Gestão e Ordenação da Paisagem, elaborada pelo Departamento de Política Territorial e Obras Públicas de Barcelona em 2006, da Carta da paisagem global, de 2009, elaborada pela Federação Internacional dos Arquitetos Paisagistas, e da Carta colombiana da paisagem, de 2010. Tais documentos visam introduzir políticas e instrumentos de conscientização da necessidade de proteger a paisagem como um monumento para guardar a memória da população (SÁ CARNEIRO; SILVA; MENEZES, 2010).

\section{CONSIDERAÇÕES FINAIS}

A representação da caatinga, em um ambiente não endêmico a tal vegetação, é um desafio. No entanto, desafio maior está em conseguir a adaptação dessas espécies, criando uma atmosfera semelhante ou igual ao que elas vivem. Um jardim, como já foi dito, é um organismo vivo e mutável. Ousado, o paisagista Roberto Burle Marx não só criou um espaço favorável ao florescimento de espécies áridas em um ambiente úmido, como também concebeu a essência de um jardim moderno brasileiro.

Hoje, após 76 anos, a conservação do jardim e o reconhecimento de sua importância enquanto jardim moderno e disseminador de cultura merecem atenção. Mesmo após seu restauro, faz-se necessário sensibilizar a população e órgãos públicos, que a praça Euclides da Cunha é um jardim representativo da história e cultura do estado de Pernambuco, além de configurar-se como uma enciclopédia botânica regional. Preservar um jardim histórico é deixar vivo, na memória coletiva da população, um testemunho paisagístico e ecológico merecedor de reconhecimento, visto ser esse o único exemplo de jardim inserido no território brasileiro com tais características.

\section{Notas}

(1) É um conjunto espacial de certa ordem de grandeza, no qual existe uma coerência no aspecto do relevo, nos tipos de solo, na vegetação, no clima e na hidrografia. Um domínio pode conter mais de um bioma e mais de um ecossistema. De modo geral, esse é um termo mais utilizado pela geografia. 
(2) Mais informações, ver: "Contribuição ao estudo da caatinga pernambucana", por Walter Egler, Revista Brasileira de Geografia, 1951.

(3) Em Estudos botânicos do Nordeste, v. 3, 1923.

\section{Bibliografia}

AB'SÁBER, Aziz Nacib. Os domínios de natureza do Brasil: potencialidades paisagísticas. São Paulo: Ateliê Editorial, 2003. BERQUE, Augustin. Paisagem, meio, história. In: BERQUE, Augustin et al. Cinco proposições para uma teoria da paisagem. Paris: Champ, 1994.

CARTA DE ATENAS, 1931. In: CURY, Isabelle (Org.). Cartas patrimoniais. Rio de Janeiro: Iphan (Edições do patrimônio), 2000

CARTA DE FLORENÇA, 1981. In: Cartas patrimoniais. Rio de Janeiro: Iphan (Edições do patrimônio), 2000.

CARTA DE VENEZA, 1964. In: Cartas patrimoniais. Rio de Janeiro: Iphan (Edições do patrimônio), 2000.

CASTRO, Carolina Florio; JATOBÁ, Luciano de Oliveira. Contribuição ao ensino do tema: "Formações Vegetais no Brasil" - um olhar sobre a vegetação no estado de Pernambuco: as caatingas. Anais. Porto Alegre: Universidade Federal do Rio Grande do Sul, 2010.

COSTA, Lúcia Maria Sá Antunes. Burle Marx e o paisagismo no Brasil contemporâneo. Revista Municipal de Engenharia, Rio de Janeiro, [s/n], p. 23-28, 1999.

DE ANGELIS, Bruno Luiz Domingos; DE ANGELIS NETO, Generoso. Jardins históricos: introduzindo a questão. Paisagem e ambiente - ensaios, São Paulo: FAUUSP, n. 19, p. 32-48, 2004.

DELPHIM, Carlos Fernando de Moura. Manual intervenções em jardins históricos. Brasília: Iphan, 2005.

EGLER, Walter Alberto. Contribuição ao estudo da caatinga pernambucana. Revista Brasileira de Geografia, Rio de Janeiro: IBGE, ano 13, n. 4, p. 577-590, 1951.

GUERRA, Abilio. Lucio Costa, Gregori Warchavchik e Roberto Burle Marx: síntese entre arquitetura e natureza tropical. Vitruvius: Arquitextos, São Paulo, [s/n] , p. 1-1, 2002. Mensal. Disponível em: <http://www.vitruvius.com.br/ revistas/read/arquitextos/03.029/740>. Acesso em: 10 out. 2009.

LEAL, Inara Roberta; TABARELLI, Marcelo; SILVA, José Maria Cardoso. Ecologia conservação da caatinga. 3. ed. Recife: Ed. Universitária da UFPE, 2008.

LEENHARDT, Jacques. École des haustes études en Sciences sociales, Paris. In: TERRA, Carlos; ANDRADE, Rubens (Org.). Paisagens culturais contrastes sul-americanos. Rio de Janeiro: Escola de Belas Artes, 2008.

MARX, Roberto Burle. Jardins e parques do Recife. Diário da Tarde, Recife, 14 mar. 1935, p. 1-1.

. Panorámica de la arquitetura latino-americana (Depoimento). In: XAVIER, Alberto (Org.). Depoimento de uma geração: arquitetura moderna brasileira. São Paulo: CosacNaify, p. 297-304, 2003.

Considerações sobre arte brasileira. In: TABACOW, José. Roberto Burle Marx: arte e paisagem: conferências escolhidas. São Paulo: Nobel, 1987.

METZGER, Jean Paul. O que é ecologia de paisagem? Biota Neotropica, Campinas, v. 1, n. 1-2, p. 1-9, 2001. Disponível em: <www.biotaneotropica.org.br>. Acesso em: 25 set. 2010.

MINISTÉRIO DA AGRICULTURA. SUDENE/DNR. Levantamento exploratório. Reconhecimento de solos do estado de Pernambuco. In: XVI ENCONTRO NACIONAL DE GEÓGRAFOS, CRISES, PRÁXIS E AUTONOMIA: ESPAÇOS DE RESISTÊNCIA E ESPERANÇA, 1973, Recife. Anais... Recife, 1973.

OLIVEIRA, Ana Rosa de. Entrevista com Carlos de Moura Delphim: Vitruvius: Entrevista, São Paulo, p. 1-6, out. 2003. Mensal. Disponível em: <http://www.vitruvius.com.br/revistas/read/entrevista/04.016/3334? page=4>. Acesso em: 25 set. 2010.

OLIVEIRA, Fabiano Lemes. O lugar do jardim: debates sobre a criação de uma paisagem moderna e brasileira. In: SÁ CARNEIRO, Ana Rita; BERTRUY, Ramona Pérez. Jardins históricos brasileiros e mexicanos. Recife: Editora Universiłária, 2009.

SÁ CARNEIRO, Ana Rita. A articulação dos espaços públicos na paisagem do Recife. In: ENCONTRO NACIONAL DE ENSINO DE PAISAGISMO EM ESCOLAS DE ARQUITETURA E URBANISMO NO BRASIL (ENEPEA), 2002, Recife. Anais... Recife: Universidade Federal de Pernambuco, 2002. 
SÁ CARNEIRO, Ana Rita; SILVA, Aline Figuerôa; MAFRA, Fátima. A paisagem do sertão no jardim de Burle Marx. Olinda: Centro de Estudos Avançados da Conservação Integrada - textos para discussão. (Série Identificação do Patrimônio) 2007.

SÁ CARNEIRO, Ana Rita; SILVA, Joelmir Marques; MENEZES, Patrícia Carneiro. As unidades de paisagem cultural além dos jardins de Burle Marx no Recife. In: 1 COLÓQUIO IBERO-AMERICANO, 2010, Belo Horizonte. Anais... Belo Horizonte: Universidade Federal de Minas Gerais, 2010.

SÁ CARNEIRO, Ana Rita. Restauração dos jardins das cactáceas de Burle Marx. In: SÁ CARNEIRO, Ana Rita; BERTRUY, Ramona Pérez. Jardins históricos brasileiros e mexicanos. Recife: Editora Universitária, 2009.

SIQUEIRA, Vera Beatriz. Burle Marx. São Paulo: CosacNaify, 2004.

TURNER, Monica. Landscape ecology: what is the state of the science? Annu. Rev. Ecol. Evol. Syst. Califórnia: Stanford University, n. 36, p. 319-344, 2004.

\section{Agradecimentos}

Os autores agradecem ao CNPq e à Capes pela concessão da bolsa de mestrado do primeiro e do segundo autores, respectivamente. 